\title{
Adult Life Adjustment of Vulnerable Youths. The Relationship Between Criminal History, Employment History and Adult Life Outcomes
}

\author{
Janna Verbruggen ${ }^{1}$ - Victor R. van der Geest ${ }^{2,3}$. \\ Arjan A. J. Blokland ${ }^{2,4}$
}

Received: 6 August 2015 /Revised: 9 August 2016 / Accepted: 16 August 2016 /

Published online: 10 September 2016

(C) Springer International Publishing AG 2016

\begin{abstract}
Purpose This article examines adult outcomes of vulnerable youths.

Methods The sample consists of 251 boys and girls who were institutionalized in a Dutch juvenile justice institution in the 1990s. Information on personal and childhood characteristics was extracted from treatment files that were compiled during their stay in the institution. In addition, conviction data was used to determine subjects' criminal careers. Conducting face-to-face interviews with these former JJI detainees when they were on average 34 years old, we collected retrospective information on employment history and several important current life course outcomes. Group-based trajectory modeling was used to identify distinct offending and employment groups.

Results Results showed that previously institutionalized youths experience difficulties adjusting to conventional adult life. Most personal and childhood characteristics exert no significant effect on adult outcomes. Criminal behaviour in young adulthood does
\end{abstract}

Janna Verbruggen

verbruggenj@ cardiff.ac.uk

Victor R. van der Geest

v.vander.geest@vu.nl

Arjan A. J. Blokland

ablokland@nscr.nl

1 Cardiff University, School of Social Sciences, Cardiff Centre for Crime, Law and Justice, Glamorgan Building, King Edward VII Avenue, Cardiff CF10 3WT, UK

2 Netherlands Institute for the Study of Crime and Law Enforcement (NSCR), Amsterdam, The Netherlands

3 VU University Amsterdam, Department of Criminal Law and Criminology, Amsterdam, The Netherlands

4 Leiden University, Institute for Criminal Law and Criminology, Leiden, The Netherlands 
impact adult life outcomes, as the two chronic offender groups show more difficulties in conventional adult life domains. Employment is associated with better adult outcomes, as the two employment groups that have an increasing or high employment rate in adulthood show higher levels of adult life adjustment.

Conclusions Adult life adjustment in this sample of previously institutionalized youths is mainly explained by events during young adulthood, and not so much by childhood risk factors. Ties to employment appear to facilitate transitions in other life domains, thereby promoting life success in adulthood.

Keywords Adult life adjustment - Life course - Criminal convictions · Employment · Trajectories

\section{Introduction}

In the Netherlands, yearly, over 4000 youths are institutionalized in juvenile justice or youth care institutions because there are serious concerns about their behaviour and development $[9,30]$. These youths represent a particularly vulnerable group, as they are generally characterized by troubled backgrounds. For example, they often come from adverse family situations, have experienced victimization, show academic failure, suffer from psychological problems and many exhibit serious behavioural problems and delinquency. As these youths transition to adulthood, they tend to face additional problems, for which they have less resources to cope with, and therefore may experience difficulties adapting to conventional adult social roles [44]. Their vulnerable background and problematic behaviour also place them at risk of developing a persistent pattern of criminal behaviour in adulthood (e.g. [38]), which further reduces their long-term life chances.

As of yet, we know very little about the adult outcomes of vulnerable youths. Retrospectively, adult offenders, especially those with a long history of offending, often report adverse conditions during their early life, but prospective knowledge about the extent to which vulnerable youths succeed in making a successful transition to adulthood and end up leading conventional lives is scarce. How are these youths progressing in conventional life domains such as employment, intimate relationships, parenthood and health? To what extent does their vulnerable background reduce their life chances? To what extent does a history of criminal involvement affect their adjustment in adult life? And to what extent does employment - the life domain most targeted by interventions - contribute to adult life success? Finding answers to these questions is important, not only for detecting undesirable life careers and marginalization, but also for preventing major hidden societal costs like those resulting from these youths' criminal behaviour, unemployment, welfare dependency and health care expenditures $[6,48]$. Therefore, the current study examines predictors of adult life adjustment of vulnerable youths in the Netherlands, by studying a sample of 251 previously institutionalized adults, using both officially registered longitudinal data and self-reported data collected in face-to-face interviews.

\section{Theory}

According to life course theories, the transitional phase between adolescence and adulthood plays an important role in determining an individual's opportunities and life 
chances. While with age most youths start to take up adult social roles such as work, marriage and parenthood, the conditions affecting the extent to which youths benefit from these life course transitions may differ greatly between individuals. Previously institutionalized youths, who are characterized by vulnerable backgrounds, behavioural problems and delinquency, may have limited resources to exploit the opportunities presented to them to strengthen their social position and raise their life chances. Due to childhood risk factors and early institutionalization, they may also face structural and social disadvantage, cutting off opportunities to increase their human capital and causing difficulties in achieving long-term life success [44, 54].

Some theorists suggest that missing out on the opportunities to adjust to adult roles is due to the same underlying predisposition that caused their problem behaviour in early life in the first place. In this respect, Gottfredson and Hirschi [25] argue that low self-control, which is assumed to remain relatively stable after childhood, causes (continued involvement in) criminal behaviour and is expected to have long-term negative consequences in other life domains as well, such as unemployment and substance abuse. According to this static view, vulnerable youths characterized by problematic backgrounds are predetermined to end up doing poorly in conventional adult life domains. Life course theories, however, suggest that childhood risk factors alone cannot predict the long-term differences in life success, related to school, employment and crime. Instead, they emphasize that social bonds, opportunities and social stigma due to past criminal involvement play an important role in explaining differences in life chances (e.g. [51]).

One of the key transitions in early adulthood and a possible marker of future life success is employment. Work not only generates income and therefore contributes to financial independence [2], but it also provides structure to everyday life, generates feelings of usefulness, and purpose and is a source of social contacts and status [27, 28]. Because of this, employment is of great importance for one's identity, wellbeing and psychological health [45]. Especially for criminally involved youth, employment can be crucial to help build a conventional identity, to foster transitions to other adult roles, and to adopt a non-criminal lifestyle $[12,51]$. Vulnerable youths, however, are at increased risk of experiencing difficulties in the domains of education and employment. Prior criminal involvement, contact with the criminal justice system, and institutionalization can be taken as signaling negative characteristics and block opportunities for connecting to conventional domains [3,33], for example when a certificate of good conduct is required to obtain a job. When in reaction to experiencing blocked opportunities, these youths again turn to crime and deviance, they are in danger of becoming trapped in a downward spiral of cumulative disadvantage, and may find that conventional opportunities that can help them live successful lives are getting more and more out of reach [52]. Whereas previously institutionalized youths who continue to engage in criminal behaviour are at risk of increasing marginalization, those who do manage to find employment may break out of the vicious circle and start increasing their chances to become established in adult life domains.

\section{Adult Outcomes of Vulnerable Youths}

Longitudinal studies following vulnerable or criminal youths well into adulthood are scarce. The few existing studies that do have a long enough follow-up usually focus 
solely on outcomes in terms of (young) adult criminal behaviour (e.g. [46, 60]), and to date, little research attention is devoted to outcomes in other adult life domains. As a result, not much is known about long-term adult outcomes of vulnerable youths in important conventional life domains, such as the labor market, family life and health.

The few studies that have paid attention to adult outcomes of vulnerable youths have examined different aspects of criminal history in relation to adult functioning. To begin with, research indicates that criminal involvement is related to poorer adult functioning. To illustrate, Sampson and Laub $[32,51]$ used the 'Unraveling Juvenile Delinquency' study by Glueck and Glueck [23, 24], in which 500 delinquent boys and a matched group of 500 non-delinquent boys were followed from ages 14 to 32, to consider multiple life domains in addition to criminal development. Although their key interest was explaining criminal desistance patterns, they also studied adult outcomes for the delinquent and non-delinquent boys and found continuity in troublesome behaviour into young and middle adulthood. Juvenile delinquency was not only related to later criminal behaviour, but also to negative outcomes in other life domains, such as employment and family life. For example, Sampson and Laub found that delinquent boys were more likely than their non-delinquent counterparts to experience job instability, as well as being economically dependent up to age 32 . In addition, delinquents were more likely to get divorced or separated and to have weak attachment to their spouses [51].

In addition, attention has been paid to the relationship between the level of criminal involvement and the level of adult functioning, indicating that outcomes in adulthood are worse for those delinquents with a more extensive criminal history. For example, using data from the Cambridge Study in Delinquent Development, a longitudinal study in which 411 boys from South London were followed from age eight to adulthood, Farrington et al. [17] studied adult life adjustment at age 48 for persistent offenders, desisters, late onset offenders and never convicted men, the latter being the largest group. Using self-report information collected at ages 32 and 48, the researchers determined to what extent these men were living 'successful lives', defined by doing well in six out of nine important life domains, including employment, intimate relationships and mental health. At age 32, almost $80 \%$ of the men lived successful lives, and at age 48, this percentage had increased to almost $90 \%$. However, when analyzing life success among active offenders, the study shows that at age 32, only $42 \%$ of all persistent offenders lived successful lives, compared to $90 \%$ of those who were not convicted. At age 48, despite an overall increase in life success, the percentage of persisters living a successful life was still the lowest by far [17].

In a follow-up study, also using the Cambridge data, Piquero et al. [47] used developmental trajectories of criminal convictions up to age 40 , in addition to childhood risk factors, to predict 'life failure' (the opposite of the abovementioned measure of 'life success') at age 48. This study showed that, even when controlling for early risk factors, the two groups with the most persistent offending patterns - the very low rate chronic offenders and the high-rate chronic offenders - experienced significantly more life failure at age 48 ([47], see also [29]).

Moreover, in an earlier study, Moffitt et al. [39] examined adult outcomes at age 26 for life course persistent offenders (males who showed extreme antisocial behaviour in both childhood and adolescence; LCP), adolescence limited offenders (males who displayed extreme antisocial behaviour only in adolescence; AL), a recovery group 
(extreme antisocial behaviour in childhood but not in adolescence), abstainers (no antisocial behaviour in childhood and adolescence), and an unclassified group (consisting of males who showed normative antisocial behaviour). Looking at a large number of adult outcomes at age 26 , the findings revealed that, in general, the LCP and AL males fared worse in a variety of life domains compared to the other groups, and that problems were often worst for LCP males. To illustrate, LCP men showed more as well as more serious offending behaviour in adulthood, more often experienced mental health problems, had worse problems with alcohol, had more problems at work, had spent more time unemployed, and more often received benefits. Moreover, using a scale consisting of ten adult adjustment problems (comprising for example conviction records, a substance dependence diagnosis, receiving benefits and long-term unemployment), LCP men experienced significantly more problems than all other groups [39].

Nilsson and Estrada [43] conducted a longitudinal study in which they followed a Swedish birth cohort - comprising both males and females - to age 48. They employed a similar classification as Farrington et al. [17] by distinguishing between persisters, desisters, late onset offenders and unconvicted men and women and studied adult life course conditions, such as employment and family formation, for these four groups. Results showed that adult outcomes of desisters were comparable to the outcomes of those never convicted. However, men and women who were registered for crime both as youths and as adults (the persisters) showed the poorest outcomes at age 48. For example, employment participation among those who were convicted was lower compared to those never convicted and the proportion receiving welfare or disability pensions was considerably higher among persisters than among those never convicted. Furthermore, a large proportion of the male and female persisters was living alone at age 48, as opposed to cohabitating or being married. Finally, the Nilsson and Estrada study showed that women with a history of convictions showed poorer adult outcomes than convicted men.

Furthermore, attention has been paid to examining effects of official contact with the youth justice system on outcomes in adulthood. For example, Bernburg and Krohn [4] found significant negative effects of contact with the police and the juvenile justice system in adolescence on educational achievement and employment in early adulthood for males. Moreover, Rutter et al. [50] followed a sample of boys and girls who were institutionalized in group homes because their parents were unable to take care of them, and a control group of youths who were not institutionalized. They demonstrated that, compared to the controls, previously institutionalized men and women showed worse outcomes with regard to psychosocial functioning, a measure that included living conditions, work, marriage, psychopathology, and crime. Using propensity score matching, Gilman et al. [22] studied the long-term consequences of juvenile incarceration on functioning in adulthood. Their findings indicate that youths who were institutionalized in adolescence were more likely to have alcohol abuse problems and to receive public assistance between ages 27 and 33 compared to youths who did not experience institutionalization.

Taken together, only a small number of studies have examined adult outcomes of vulnerable youths. These studies show that, in general, people with a history of serious behavioural problems, delinquency or institutionalization in adolescence are more 
likely to experience difficulties in conventional adult life domains. This is especially so for those with a more extensive criminal history (e.g. [17]). However, some important features of the currently available studies potentially limit the generalizability of these conclusions. First, with the exception of the Swedish study by Nilsson and Estrada [43], these studies were carried out in Anglo-Saxon countries that are characterized by a sociocultural context that differs in important ways from that of other Western-European nations. For instance, whereas many US employers have access to the criminal records of potential employees, most European employers do not, or to a far more limited extent [5]. Second, the adolescents followed in these studies came of age in vastly different historical contexts. National and temporal differences in for example the penal climate, the welfare system and public health care, may impact the way in which adolescent behaviour problems relate to adult life success. Third, prior research predominantly studied male samples and, as a result, had to remain silent on the risk factors for adult life failure in vulnerable women. Finally, limited attention has been paid to examining protective factors that might help vulnerable youths make a successful transition into adulthood (e.g. [61]). To date, it is unclear to what extent employment, which is not only one of the most important adult roles, but is also the life domain that is most easily targeted by interventions, contributes to adult life adjustment. Taken together, still little is known about the extent to which vulnerable boys and girls in countries with comparatively strong social safety nets, such as the Netherlands, are able to establish themselves as adults in contemporary society, and what factors might help or hinder them in making a successful transition into adulthood.

\section{The Current Study}

Building upon the existing body of literature discussed above, the current study focuses on childhood risk factors, employment and criminal career patterns as they relate to long-term life chances of vulnerable youths. Using data from a contemporary sample of previously institutionalized Dutch men and women $(N=251)$, the current study will test whether we can prospectively identify those youths most at risk of failing to become healthy, self-sufficient, productive members of society. To do so, the study addresses the following research questions: First, what is the level of adjustment in conventional adult life domains of men and women previously institutionalized in a juvenile justice facility? Second, to what extent do personal and childhood characteristics of previously institutionalized men and women predict their level of adult life adjustment? Third, to what extent does criminal behaviour of previously institutionalized men and women, over and above personal and childhood characteristics, predict their level of adult life adjustment? And fourth and finally, to what extent does employment history of previously institutionalized men and women predict their level of adult life adjustment, when personal and childhood characteristics and criminal history are taken into account? Answers to these questions can shed light on the degree to which adult life adjustment is explained by stable individual characteristics, as stated by static theories (e.g. [25]), or whether events in young adulthood, namely criminal behaviour and employment, influence adult outcomes as well, as is assumed by those taking a life course approach (e.g. [51]). 


\section{Method}

\section{Sample}

This study uses data from the 17up study, a longitudinal study following vulnerable youths well into adulthood. ${ }^{1}$ The original sample of the 17 up study comprises of 270 boys and 270 girls who were institutionalized in a Dutch judicial treatment institution for juveniles in the 1980-1990s. The boys were discharged from the institution between 1989 and 1996 and the girls between 1990 and 1999. At that time, juveniles could be referred to the judicial treatment institution based on a criminal law measure or a civil law measure. A criminal law measure could be imposed when a juvenile had committed an offense and was aged between 12 and 18. A civil law measure could be imposed when a child was under age 18 , and it was impossible for a child to remain at home, for example because of behavioural problems or an adverse family situation. All boys and girls in the sample showed serious behavioural problems, often including delinquency. During their stay, all respondents received treatment, which aimed at reducing the juveniles' problematic and delinquent behaviour, as well as providing them education.

Between July 2010 and January 2012, a follow-up study was carried out which aimed at conducting face-to-face interviews with as many of the original 540 previously institutionalized youths as possible. At the start of the follow-up study, 22 subjects $(4.1 \%)$ of the original 540 boys and girls had died. ${ }^{2}$ This observed death rate is relatively high, given that subjects are still in their 30s [7]. In addition, 14 subjects had emigrated, and five subjects were living in institutions, such as a psychiatric institution or a forensic clinic, that refused to cooperate with the study. This left 499 men and women that could be approached for an interview. These subjects first received a letter containing information about the study, after which trained interviewers approached them at home or, in some cases, in the prison or in the treatment center for psychiatric or addiction problems where they resided. Homeless subjects were approached through shelters and municipal welfare departments.

If respondents were willing to take part in the study, the actual interviews were conducted using a laptop, either at the respondent's home or at another place (for example a nearby cafe) if the respondent so desired. Interviews lasted $1.5 \mathrm{~h}$ on average and respondents received a gift voucher of $€ 25$ at the completion of the interview.

All in all, 251 respondents (118 men, 133 women) participated in the study, which comes down to a $50.3 \%$ response rate. Of those not participating, 156 individuals refused, 83 could not be contacted after six to eight attempts, four individuals were reached but were too ill to participate (due to severe psychiatric problems such as psychosis) and five individuals did not turn up (repeatedly) for their interview appointment. A response analysis was conducted to compare those who participated in the study with those who could not be approached or refused to participate. Groups were

\footnotetext{
${ }^{1}$ For this study, formal consent was obtained from the Dutch Ministry of Security and Justice. In addition, the Ethics Committee of the Faculty of Law (CERCO) of VU University approved the study and its procedures. ${ }^{2}$ As was noted by an anonymous reviewer of a previous version of this article, compared to expectations based on mortality rates in the general Dutch population a disproportionate number of individuals in the original sample died prior to the end of the current follow up, rendering the group of individuals that did survive to this age - and that are under scrutiny here - somewhat more homogeneous. In turn, this may have negatively affected the predictive value of childhood characteristics in the remaining sample.
} 
compared on a number of personal and background characteristics, living situation, employment, marital status and criminal behaviour. Responders and non-responders did not differ significantly on these characteristics besides those without an officially registered home address being under-represented in the subsample [56]. Although the subsample can thus be considered to be representative of the original sample with regard to most of the measured characteristics, those without a registered home address being under-represented in the subsample could mean that the findings regarding levels of adult life adjustment might to some extent be positively biased.

On average, respondents were interviewed 17 years after they had left the institution (17.7 years, $\mathrm{SD}=2.8)$. For men, the follow-up period is 19.4 years $(\mathrm{SD}=2.3)$ and for women 16.3 years $(\mathrm{SD}=2.3)$. The average age of the respondents at the time of the interview was 36.8 for men $(\mathrm{SD}=2.4)$ and 32.9 for women $(\mathrm{SD}=2.5)$.

\section{Measures}

\section{Personal and Childhood Characteristics}

Personal and childhood characteristics were extracted from treatment files that were constructed during the juveniles' stay in the treatment institution by a multi-disciplinary team of psychologists, psychiatrists, social workers and pedagogical staff working on the groups in the institution. These files contain for example psychological and psychiatric reports, outcomes of standardized and validated instruments, such as the Wechsler Intelligence Scale for Children-Revised and the Child Behavior Checklist, reports from the Dutch Child Protection Board and treatment evaluations. Based on the information on youths' personal and childhood characteristics present in the treatment files, for this study, we included the following variables in the analyses: adverse family situation (i.e. a sum of whether respondents grew up in a family where there was alcohol abuse, substance abuse, a parent with psychopathology, family members with a criminal history or unemployment), victimization (i.e. a sum of whether respondents experienced neglect, physical abuse or sexual abuse), psychological problems (yes/no), aggression (yes/no) and impulsiveness (yes/no). Dichotomous variables were used as this allows for a more comprehensible interpretation of the model estimates and also because not all variables were measured on an interval scale. Information on the youths' family situation and victimization was collected from reports and assessments prior to the youths' institutionalization, whereas psychological problems, aggression and impulsiveness were measured by psychologists and psychiatrists during institutionalization. Furthermore, since education is a possible protective factor important for positive adult outcomes (e.g. [4, 53]), information on education was collected in the interviews using a questionnaire, which included questions about whether respondents followed and finished an education while institutionalized or after they had left the institution.

\section{Criminal History}

Respondents' criminal history is reconstructed using officially registered information on convictions. Information on convictions was collected from judicial documentation abstracts of the Netherlands Ministry of Security and Justice. These abstracts contain 
information on every case that is registered at the public prosecutor's office. Information about the type of offense and offense date is available. Using data on convictions, a dichotomous variable was constructed, indicating whether a person was convicted for an offense between ages 12 and 17. Furthermore, based on conviction data from ages 18 to 34, developmental trajectories were estimated (described in more detail below). Convictions pertain to a wide range of offenses, such as violent offenses, property offenses, serious public order offenses, drugs offenses and weapon offenses (following a classification used by Loeber et al. [35], and as used in previous work on the 17up dataset, e.g. $[55,57,58])$. Given that minor offenses, such as vandalism and road traffic offenses, are relatively common even in the general population, convictions for minor offenses are excluded from the analyses.

\section{Employment History}

Information about employment history was collected during the interviews using a life history calendar. This is a structured instrument for gathering more reliable retrospective information about the occurrence and timing of important life events over the life course. The calendar provides the respondent with visual cues which stimulate crossdomain referencing, thereby facilitating respondents' accurate recall of the timing and duration of events and transitions in different life course domains [19]. Using the life history calendar respondents indicated for each age year whether they were employed or not. Using information on respondents' self-reported formal employment (temporary work, regular work or business ownership) in the years from ages 18 to 34, developmental employment trajectories were estimated (described in more detail below).

\section{Adult Life Adjustment}

The dependent variable in this study is respondents' level of adult life adjustment in the year they were interviewed. In the interviews, questions were asked following semistructured and structured questionnaires to collect information about several adult life domains. Based on this information, the following variables were constructed: (1) Regular accommodation: Subjects were considered to have regular accommodation when they lived in a house at the time of the interview, as opposed to living in an institution or detention center, staying at relatives or friends, or being homeless. (2) Employment: This variable measures whether respondents were formally employed (i.e. employment for which taxes are paid) at the time of the interview. (3) Intimate relationship: This variable measures whether subjects were in a romantic relationship at the time of the interview. (4) Regular contact with children: Subjects were asked whether they had children, and if so, how often they had contact with their child(ren). Respondents who had daily or weekly contact with child(ren) were coded as having regular contact with children, as opposed to respondents who had less frequent or no contact with their child(ren). (5) Satisfactory health: Using questions derived from the Dutch Health Monitor [20], respondents were asked whether they had taken medication prescribed by a doctor during the past 12 months (excluding birth control), and whether they had had contact with one of the following seven health care professionals: medical specialist, company doctor, mental health service, psychologist, psychiatrist, addiction care service, or an emergency room. Visits to general practitioners are excluded, given 
that these are relatively common. For example, in 2011, $72 \%$ of the people in the general Dutch population visited a general practitioner [21]. Based on these eight indications of health problems, respondents were considered to be in satisfactory health when they had a score of 0 or 1 and coded as having no satisfactory health situation when they scored 2 or higher. (6) Alcohol abuse and (7) Drug abuse: Items derived from the Composite International Diagnostic Interview (CIDI) were used to ask subjects whether they had used alcohol and drugs (soft and hard drugs) in the past 12 months and whether they had experienced difficulties on conventional life domains as a consequence of their alcohol or drug use. Following the criteria for alcohol abuse and drug abuse of the DSM-IV-TR, it was determined whether subjects met the criteria for alcohol abuse or drug abuse. ${ }^{3}$ (8) Self-reported crime: Using items from the International Self-Report Delinquency scale (ISRD), respondents reported whether they had committed one or more offenses (i.e. vandalism, theft, burglary, fraud, threat/assault, violent offense, sex offense and drug dealing) in the past 12 months.

All variables were coded dichotomous, with a value of 1 indicating 'adjusted' and 0 'not adjusted'. Alcohol abuse, drugs abuse and self-reported crime are taken as indictors of unsuccessful adjustment; therefore, these variables were coded as 0 when subjects were classified as having an alcohol abuse problem, a drug abuse problem, or had committed an offense. For each subject, the average level of adult life adjustment across all eight domains was calculated, with a higher value indicating a higher level of adult life adjustment. Respondents that did not have children were coded as missing on that particular life domain, as not having children does not necessarily means being 'not adjusted'. In those cases, the average value of adult life adjustment was calculated based on the values of the seven remaining life domains. Similarly, for the respondents that were incarcerated or institutionalized at the moment of the interview $(N=18)$, values on life domains that are deemed difficult or impossible to experience while incarcerated/institutionalized were coded as missing (e.g. employment during institutionalization), and the average value of adult life adjustment was calculated based on the remaining life domains. Cronbach's alpha of this scale is 0.62 , which is comparable to the measures used by Farrington et al. [17] and Piquero et al. [47] (i.e. Cronbach's alpha was 0.65 at follow-up at age 32 and 0.52 at follow-up at age 48).

The measure of adult life adjustment used in this study is based on whether individuals adopted adult roles that are thought to be markers of conventional adult life, such as employment and being in a relationship. When subjects have not attained these adult markers, they are considered to be 'unadjusted'. However, for those people, 'failure' in a certain life domain does not necessarily mean that they are not doing well. For example, an unemployed person might be satisfied with being a homemaker, and someone might be content being single instead of in a relationship. Given that we could not take these subjective perceptions of one's status in adult life domains into account, our measure of adult life adjustment—like

\footnotetext{
${ }^{3}$ One meets the criteria for alcohol abuse / substance abuse when he or she shows a maladaptive pattern of drinking / substance use, manifested by for example recurrent alcohol-related / substance-related legal problems, or recurrent use of alcohol / substance use resulting in a failure to fulfill major role obligations at work, school, or home (American Psychiatric Association [1]: 199; 214).
} 
that used in prior studies - can be considered 'conservative' in the political rather than the statistical sense of that term.

\section{Analyses}

Descriptive statistics for respondents' personal and childhood characteristics, criminal history, employment history and different dimensions and level of adult life adjustment are presented for males and females separately. Chi square tests and independent sample $t$ tests were conducted to tests for statistically significant gender differences.

Similar to Piquero et al. [47], group-based trajectory modeling [40, 42] is used to identify developmental pathways of offending in the sample. This technique identifies clusters of individuals following developmental pathways that are relatively similar in both the level and shape of offending with age [40]. Trajectories are estimated using data on convictions for serious offenses from age 18 to age 34 , which is the average age at the moment of the interview. For each respondent, conviction data up to 1 year before the moment of the interview is used, enabling us to examine the relationship between criminal history prior to the interview and adult life adjustment at the moment of the interview. Furthermore, conviction frequency is corrected for incarceration. ${ }^{4}$ Because convictions are relatively rare events, a zero-inflated Poisson model is fitted. The Bayesian information criterion (BIC) is used to determine the number of groups that best describes the data. The model estimates probabilities that a sample member belongs to each of the trajectory groups (see for more details on group-based trajectory modeling: $[41,42])$. A similar procedure is followed to identify different employment groups in the sample. Because the life history calendar provides dichotomous data about employment per age year, a logistic model is fitted to distinguish the employment trajectories.

Then, to examine to what extent personal and childhood characteristics, criminal behaviour and employment history are associated with adult life adjustment, three multiple regression models are estimated. The first model estimates effects of subjects' personal and childhood characteristics on adult life adjustment. The second model examines to what extent criminal history is related to adult life adjustment, over and above the effects of subjects' background factors, by estimating the effect of crime in adolescence, namely whether respondents are convicted between ages 12 and 17 , as well as by examining to what extent different crime trajectories in adulthood are related to adult life adjustment, by including the probabilities that a sample member belongs to each of the crime trajectory groups, as estimated by the trajectory model, in the regression analysis. Finally, the third model estimates the extent to which employment patterns in adulthood are associated with adult life outcomes, over and above personal and childhood characteristics and criminal history features, by including the probabilities that a sample member belongs to each of the employment trajectory groups in the model.

\footnotetext{
${ }^{4}$ Since offending is less likely to occur when a respondent is incarcerated, time spent incarcerated is corrected for with the following formula: Exposure $j i=1-$ (number of days incarcerated/730), where $j$ is the respondent and $i$ is the year of observation (see [55]).
} 


\section{Results}

\section{Descriptive Results}

\section{Personal and Childhood Characteristics}

As mentioned above, the boys and girls placed in juvenile justice institutions often display behavioural problems and are characterized by vulnerable family backgrounds. Behavioural problems and background characteristics giving rise to placement in the institution are described in detail in the treatment files and are summarized in Table 1. A large proportion of men $(74.2 \%)$ and women $(84.6 \%)$ were highly impulsive, and two thirds of the men and women displayed aggressive behaviour. In addition, the intelligence of around one third of the respondents was below average.

Furthermore, around two thirds of the boys $(61.9 \%)$ and girls $(61.7 \%)$ experienced psychological problems. The prevalence of psychological problems is considerably higher in our sample than what is average in the Dutch population [59]. The most common diagnoses for boys were conduct disorder (22.9\%), depression (22.9\%) and ADHD (11.0\%). Girls were most often diagnosed with depression (42.1\%). In addition, a sizable share of these girls also displayed externalizing problem behaviour, such as serious behaviour problems $(20.3 \%)$ or conduct disorder $(14.3 \%)$.

In addition, respondents grew up in adverse family environments. Girls were more likely than boys to experience problematic family conditions $\left(\chi^{2}(1, N=251)=16.01\right.$,

Table 1 Descriptive statistics for personal and childhood characteristics and education

\begin{tabular}{|c|c|c|c|c|}
\hline & \multicolumn{2}{|c|}{$\operatorname{Men}(N=118)$} & \multicolumn{2}{|c|}{ Women $(N=133)$} \\
\hline & $N$ & $\%$ & $N$ & $\%$ \\
\hline Low intelligence & 29 & 30.5 & 45 & 34.9 \\
\hline Aggression & 77 & 65.8 & 90 & 67.7 \\
\hline Impulsiveness & 72 & 74.2 & 77 & 84.6 \\
\hline Psychological problems & 73 & 61.9 & 82 & 61.7 \\
\hline Problematic family environment $* * *$ & 59 & 50.0 & 99 & 74.4 \\
\hline Alcohol abuse in family $\dagger$ & 27 & 22.9 & 44 & 33.1 \\
\hline Substance abuse in family $\dagger$ & 8 & 6.8 & 19 & 14.3 \\
\hline Psychopathology parent** & 33 & 28.0 & 62 & 46.6 \\
\hline Criminal family members* & 19 & 16.1 & 38 & 28.6 \\
\hline Unemployment in family*** & 16 & 15.7 & 31 & 23.3 \\
\hline Victimization & 100 & 84.7 & 112 & 84.2 \\
\hline Neglect* & 95 & 80.5 & 88 & 66.2 \\
\hline Physical abuse ${ }^{* *}$ & 36 & 30.5 & 68 & 51.1 \\
\hline Sexual abuse ${ }^{* * *}$ & 8 & 6.8 & 44 & 33.1 \\
\hline Finished an education during stay in the institution*** & 67 & 57.8 & 11 & 8.3 \\
\hline Finished an education after stay in institution & 58 & 51.3 & 67 & 52.3 \\
\hline
\end{tabular}

${ }^{\dagger} p<0.10 ; * p<0.05 ; * * p<0.01 ; * * * p<0.001$ 
$p<.001)$. For example, more girls than boys had at least one parent with mild or severe psychopathology, and girls more often than boys grew up in a family where alcohol abuse, substance abuse, criminal family members, or long-term unemployment were present.

Moreover, a large part of the sample, almost $85 \%$, experienced at least one form of victimization before they entered the institution. Most common was neglect, which was more often experienced by boys $(80.5 \%)$ than by girls $(66.2 \%)\left(\chi^{2}(1, N=251)=6.51\right.$, $p<.05)$. Furthermore, over half of the women were victims of physical abuse, and one third of the women were victims of sexual abuse, while fewer men were physically $\left(30.5 \% ; \chi^{2}(1, N=251)=10.95, p<.01\right)$ or sexually abused $\left(6.8 \% ; \chi^{2}\right.$ $(1, N=251)=26.33, p<.001)$.

Finally, data from the interviews shows that the majority of boys and girls followed vocational training during their stay at the institution. When they left the institution, a much larger proportion of the boys $(57.8 \%)$ than girls $(8.3 \%)$ had a diploma $\left(\chi^{2}(1, N=248)=69.95, p<.001\right)$, possibly because females were somewhat younger when they were discharged from the institution. Over $70 \%$ of men and women report that they attended some form of education after their stay in the institution, and more than half of the respondents also received a diploma (Table 1).

In sum, while childhood risk factors and early behavioural problems are more prevalent in the current sample compared to the general population-reflecting the vulnerable nature of the current sample - variation in these factors still remains that might be linked to adult outcomes.

\section{Criminal History}

The majority of boys $(89.0 \%)$ and girls $(97.7 \%)$ received treatment in the institution under a civil law measure, and the others, 13 boys and three girls, were institutionalized based on a criminal law measure. Boys stayed in the institution for an average of 21 months ( $\mathrm{SD}=14$ months) and were discharged at an average age of $17.3(\mathrm{SD}=1.4)$. The girls' stay in the institution was shorter, 13 months ( $\mathrm{SD}=8$ months) on average $(\mathrm{t}(190.16)=5.64, p<.001)$, and girls left the institution at a younger age than boys (age 16.6, $\mathrm{SD}=1.3)(\mathrm{t}(249)=4.58, p<.001)($ Table 2$)$.

Prior to age 18 , the majority of boys $(81.4 \%)$ were convicted of at least one offense. Within the convicted group, boys averaged almost six convictions $(\mathrm{SD}=5.21)$. More than half of the girls $(52.6 \%)$ were convicted of an offense before age 18 . Within the group of female offenders, girls were convicted 2.4 times on average $(\mathrm{SD}=2.5)$. Boys were more likely to be convicted prior to age 18 than girls $\left(\chi^{2}(1, N=251)=23.03\right.$, $p<.001)$, and their average number of juvenile convictions was higher $(\mathrm{t}(143.86)=5.42, p<.001)$.

From age 18 onwards, men were more often convicted than women $\left(\chi^{2}(1\right.$, $N=251)=32.83, p<.001$ ); over $80 \%$ of the men and almost $50 \%$ of the women were convicted for an offense at least once (see Table 2). Male offenders were also convicted more frequently $(\mathrm{t}(122.80)=5.25, p<.001)$, with male offenders being convicted 13.5 times on average $(\mathrm{SD}=16.3)$, while female offenders were convicted 4.2 times $(\mathrm{SD}=5.1)$. Adjusting for the length of the follow-up, this boils down to an average rate of $0.72(\mathrm{SD}=0.85)$ convictions per year for the criminally active men in the sample, compared to an average rate of $0.28(\mathrm{SD}=0.33)$ for the criminally active women, which again is a significant difference $(\mathrm{t}(135.32)=4.58, p<.001)$. 
Table 2 Descriptive statistics for criminal history and information on conviction trajectories from ages 18 to 34

\begin{tabular}{|c|c|c|c|c|}
\hline & \multicolumn{2}{|c|}{$\operatorname{Men}(N=118)$} & \multicolumn{2}{|c|}{ Women $(N=133)$} \\
\hline & $N(\%)$ & $\mathrm{M}(\mathrm{SD})$ & $N(\%)$ & $\mathrm{M}(\mathrm{SD})$ \\
\hline $\begin{array}{l}\text { Institutionalized based on } \\
\text { civil law measure** }\end{array}$ & $105(89.0)$ & & $130(97.7)$ & \\
\hline $\begin{array}{l}\text { Length of stay in institution } \\
\text { (in months) } \text { * }^{* * *}\end{array}$ & & $21.4(13.5)$ & & $13.3(8.3)$ \\
\hline Age left institution*** & & $17.3(1.4)$ & & $16.6(1.3)$ \\
\hline Convicted < age $18 * * *$ & $96(81.4)$ & & $70(52.6)$ & \\
\hline $\begin{array}{l}\text { Average number of } \\
\text { convictions }<\text { age } 18^{* * *}\end{array}$ & & $5.69(5.21)$ & & $2.39(2.47)$ \\
\hline Convicted $>$ age $18 * * *$ & $97(82.2)$ & & $63(47.4)$ & \\
\hline $\begin{array}{l}\text { Average number of } \\
\text { convictions }>\text { age } 18 * * *\end{array}$ & & $13.48(16.27)$ & & $4.19(5.11)$ \\
\hline $\begin{array}{l}\text { Convictions in adulthood } \\
\quad(\text { lambda })^{* * *}\end{array}$ & & $0.72(0.85)$ & & $0.28(0.33)$ \\
\hline \multicolumn{5}{|c|}{ Conviction trajectories from ages 18 to 34} \\
\hline & $\begin{array}{l}\text { Group 1: } \\
\text { low-rate } \\
\text { desisters }\end{array}$ & $\begin{array}{l}\text { Group 2: } \\
\text { high-rate } \\
\text { desisters }\end{array}$ & $\begin{array}{l}\text { Group 3: } \\
\text { low-rate } \\
\text { chronics }\end{array}$ & $\begin{array}{l}\text { Group 4: } \\
\text { high-rate } \\
\text { chronics }\end{array}$ \\
\hline$N$ & 148 & 29 & 51 & 23 \\
\hline$\%$ of the sample & 59.0 & 11.6 & 20.3 & 9.2 \\
\hline Mean posterior probability & 0.89 & 0.85 & 0.92 & 0.98 \\
\hline BIC value & -2482.72 & & & \\
\hline
\end{tabular}

${ }^{\dagger} p<0.10 ; * p<0.05 ; * * p<0.01 ; * * * p<0.001$

When looking at the results from group-based trajectory modeling that was applied to the conviction data, it becomes clear that there are substantial differences in adult criminal involvement in the sample. Based on the BIC value and other criteria to assess model fit mentioned by Nagin [42], a four-group model was found to be the best solution. The mean posterior probabilities of the four-group model range from 0.85 to 0.98 , which indicates that subjects have a high probability of being assigned to a particular group (Table 2). The following four groups were identified. The largest group comprises the low-rate desisters $(59.0 \%)$, who show a conviction rate that is close to zero throughout the observation period, from ages 18 to 34 . A group of high-rate desisters (11.6\%) start with a high conviction rate at age 18 , peak at age 19 and show a sharp decrease in their early 20 s. The low-rate chronics $(20.3 \%)$ show a steady but slowly decreasing conviction rate from ages 18 to 34 . Finally, the high-rate chronics $(9.2 \%)$ have a high conviction rate from ages 18 to 34 that peaks around age 23. At age 34, their conviction rate is still substantially higher than that of the other groups (Fig. 1).

Thus, despite adult criminal behaviour being prevalent in our sample, there are substantive differences in both the level and shape of the criminal pathways these vulnerable youths follow during their adult years. 


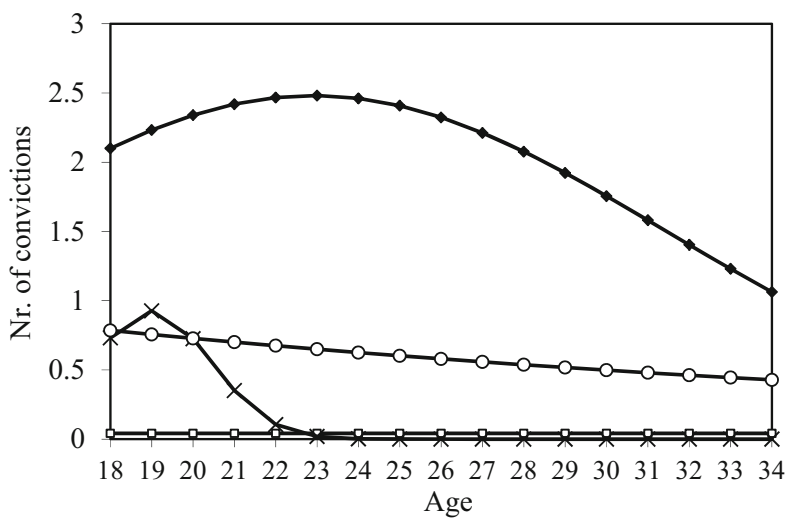

$\longrightarrow$ Group 1: low-rate desisters $(59,0 \%)$

* Group 2: high-rate desisters $(11.6 \%)$

$\rightarrow-$ Group 3: low-rate chronics $(20.3 \%)$

$\longrightarrow$ Group 4: high-rate chronics $(9.2 \%)$

Fig. 1 Conviction trajectories from ages 18 to 34

\section{Employment History}

The majority of men $(89.7 \%)$ and women $(84.0 \%)$ were employed at least once after the age of 18 . However, among those ever employed, men on average were employed for two thirds of the observation period $(\mathrm{M}=0.66, \mathrm{SD}=0.34)$, while women were employed little over half of the follow-up period $(M=0.58, \mathrm{SD}=0.32$ ) (Table 3 ).

Similar to criminal involvement in adulthood, group-based trajectory modeling demonstrated that within the sample substantial differences exist in employment patterns. Four employment trajectories were identified. The mean posterior probabilities of the four-group model range from 0.91 to 0.97 , indicating that subjects have a very high probability of being assigned to the group (Table 3). A substantial group $(27.1 \%)$ is chronically unemployed between ages 18 and 34 . A second group (23.9\%)

Table 3 Descriptive statistics for employment history and information on employment trajectories from ages 18 to 34

\begin{tabular}{|c|c|c|c|c|}
\hline & \multicolumn{2}{|l|}{$\operatorname{Men}(N=118)$} & \multicolumn{2}{|c|}{ Women $(N=133)$} \\
\hline & $N(\%)$ & $\mathrm{M}(\mathrm{SD})$ & $N(\%)$ & $\mathrm{M}(\mathrm{SD})$ \\
\hline Employed in adulthood & $104(89.7)$ & & $110(84.0)$ & \\
\hline $\begin{array}{l}\text { Employment in adulthood } \\
\text { (yearly) }\end{array}$ & & $0.66(0.34)$ & & $0.58(0.32)$ \\
\hline \multicolumn{5}{|c|}{ Employment trajectories from ages 18 to 34} \\
\hline & $\begin{array}{l}\text { Group 1: } \\
\quad \text { chronically } \\
\text { unemployed }\end{array}$ & $\begin{array}{l}\text { Group 2: } \\
\text { decreasing } \\
\text { employed }\end{array}$ & $\begin{array}{l}\text { Group 3: } \\
\text { increasing } \\
\text { employed }\end{array}$ & $\begin{array}{l}\text { Group 4: } \\
\text { continuously } \\
\text { employed }\end{array}$ \\
\hline$N$ & 68 & 60 & 46 & 77 \\
\hline$\%$ of the sample & 27.1 & 23.9 & 18.3 & 30.7 \\
\hline $\begin{array}{l}\text { Mean posterior } \\
\text { probability }\end{array}$ & 0.97 & 0.91 & 0.95 & 0.96 \\
\hline $\mathrm{BIC}$ value & -1480.92 & & & \\
\hline
\end{tabular}


starts with a high employment rate at age 18 but shows a decreasing employment rate with age. A third group (18.3\%) shows an opposite development with a low employment rate at age 18 that increases with age. The fourth group (30.7\%) is continuously employed throughout the observation period (Fig. 2).

\section{Adult Life Adjustment}

Descriptives for the different dimensions of adult life adjustment are presented in Table 4. These dimensions were measured at the time of the interview, when the male respondents were on average 36.8 years old $(\mathrm{SD}=2.4)$ and the females 32.9 years old $(\mathrm{SD}=2.5)$. When describing how the respondents are doing on the different life domains below, comparisons will be made with general population studies. These comparisons serve to shed some light on the differences in adult outcomes between the general population and the vulnerable group under study as a whole, as well as to provide a yardstick by which to compare differences between subgroups based on developmental trajectories. However, it should be noted that it is difficult to make any claims based on these comparisons, as it was impossible to compare the sample under study with general population samples using statistical analyses.

(1) Regular accommodation. At the time of the interview, $80.5 \%$ of the male respondents and $91 \%$ of the female respondents had a satisfactory housing situation, which means living in a regular house, as opposed to being homeless, staying with relatives or friends, or living in an institution or detention center. Twelve percent of the men and $3 \%$ of the women were institutionalized at the time of the interview. Compared to women, men were less likely to be in regular accommodation $\left(\chi^{2}(1, N=251)=5.71, p<.05\right)$ and more likely to be institutionalized $\left(\chi^{2}(1, N=251)=7.36, p<.01\right)$. Of those institutionalized, seven men and one woman were imprisoned, four men and two women were treated in a forensic clinic, and three men and one woman were institutionalized in a psychiatric institution. Another $7 \%$ of the respondents was either homeless ( 2 men, no women) or lived with family or friends ( 7 men and 8 women). The institutionalization rate in the sample is relatively high compared to the general Dutch population. To illustrate,

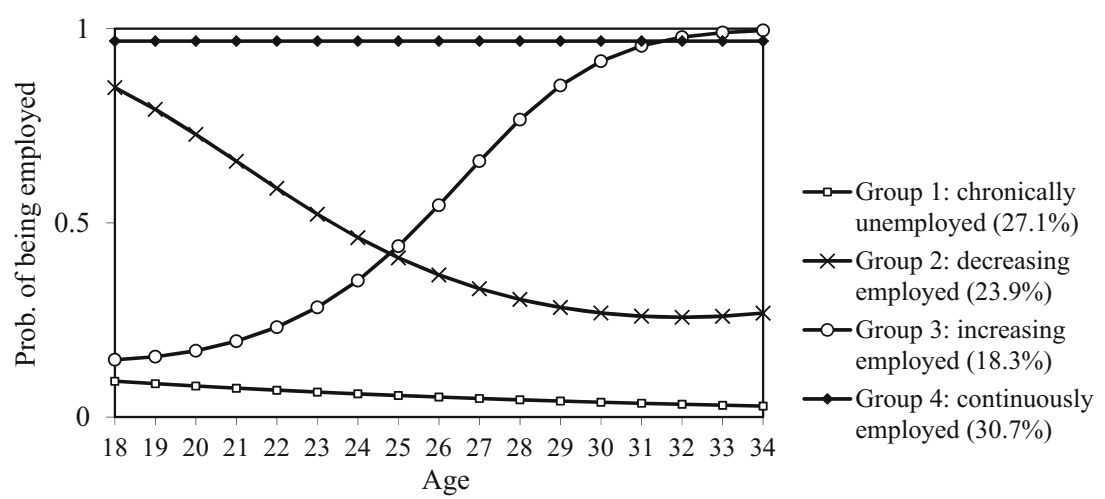

Fig. 2 Employment trajectories from ages 18 to 34 
Table 4 Descriptive statistics for adult life adjustment

\begin{tabular}{|c|c|c|c|c|}
\hline & \multicolumn{2}{|l|}{$\operatorname{Men}(N=118)$} & \multicolumn{2}{|c|}{ Women $(N=133)$} \\
\hline & $N$ & $\%$ & $N$ & $\%$ \\
\hline $\begin{array}{l}\text { (1) Regular } \\
\text { accommodation* }\end{array}$ & 95 & 80.5 & 121 & 91.0 \\
\hline $\begin{array}{l}\text { Incarcerated or } \\
\text { institutionalized } * *\end{array}$ & 14 & 11.9 & 4 & 3.0 \\
\hline Homeless & 2 & 1.7 & 0 & 0.0 \\
\hline $\begin{array}{l}\text { Other (e.g. staying at } \\
\text { family/friends) }\end{array}$ & 7 & 5.9 & 8 & 6.0 \\
\hline (2) Employed* & 55 & 46.6 & 50 & 37.6 \\
\hline Fulltime employed* & 45 & 38.1 & 32 & 24.1 \\
\hline (3) In a relationship & 68 & 58.6 & 88 & 66.7 \\
\hline Cohabitating & 45 & 38.8 & 57 & 43.2 \\
\hline Married & 17 & 14.7 & 12 & 9.1 \\
\hline $\begin{array}{l}\text { (4) Regular contact with } \\
\text { child(ren)* }\end{array}$ & 46 & 39.0 & 91 & 68.4 \\
\hline Child(ren) $* * *$ & 66 & 55.9 & 104 & 78.8 \\
\hline (5) Satisfactory health & 54 & 50.0 & 60 & 47.6 \\
\hline (6) Alcohol abuse *** & 48 & 45.7 & 27 & 22.3 \\
\hline (7) Drug abuse** & 38 & 37.6 & 26 & 21.3 \\
\hline (8) Self-reported crime & 34 & 34.0 & 27 & 25.2 \\
\hline $\begin{array}{l}\text { Average adult life } \\
\text { adjustment** }\end{array}$ & $\mathrm{M}=0.61$ & $\mathrm{SD}=0.28$ & $M=0.69$ & $\mathrm{SD}=0.22$ \\
\hline Conviction trajectories & $\begin{array}{l}\text { Group 1: } \\
\text { low-rate } \\
\text { desisters }\end{array}$ & $\begin{array}{l}\text { Group 2: } \\
\text { high-rate } \\
\text { desisters }\end{array}$ & $\begin{array}{l}\text { Group 3: } \\
\text { low-rate } \\
\text { chronics }\end{array}$ & $\begin{array}{c}\text { Group 4: } \\
\text { high-rate } \\
\text { chronics }\end{array}$ \\
\hline $\begin{array}{l}\text { Average adult life } \\
\text { adjustment } * * *\end{array}$ & $\begin{array}{l}\mathrm{M}=0.71 \\
\quad(\mathrm{SD}=0.21)\end{array}$ & $\begin{array}{l}M=0.73 \\
\quad(S D=0.22)\end{array}$ & $\begin{array}{l}\mathrm{M}=0.51 \\
\quad(\mathrm{SD}=0.28)\end{array}$ & $\begin{array}{l}\mathrm{M}=0.49 \\
\quad(\mathrm{SD}=0.21)\end{array}$ \\
\hline Employment trajectories & $\begin{array}{l}\text { Group 1: } \\
\text { chronically } \\
\text { unemployed }\end{array}$ & $\begin{array}{l}\text { Group 2: } \\
\text { decreasing } \\
\text { employed }\end{array}$ & $\begin{array}{l}\text { Group 3: } \\
\text { increasing } \\
\text { employed }\end{array}$ & $\begin{array}{l}\text { Group 4: } \\
\text { continuously } \\
\text { employed }\end{array}$ \\
\hline $\begin{array}{l}\text { Average adult life } \\
\text { adjustment*** }\end{array}$ & $\begin{array}{l}\mathrm{M}=0.60 \\
\quad(\mathrm{SD}=0.23)\end{array}$ & $\begin{array}{l}M=0.57 \\
\quad(S D=0.26)\end{array}$ & $\begin{array}{l}\mathrm{M}=0.73 \\
\quad(\mathrm{SD}=0.23)\end{array}$ & $\begin{array}{l}M=0.72 \\
\quad(S D=0.23)\end{array}$ \\
\hline
\end{tabular}

A Games-Howell post-hoc test showed that the average level of adult life adjustment differs between conviction groups: Group $1>$ groups 3, 4; group $2>$ groups 3, 4; group $3<$ groups 1 , 2; group $4<$ groups 1,2

A Tukey's post-hoc test showed that the average level of adult life adjustment differs between employment groups: Group $1<$ groups 3, 4; group $2<$ groups 3, 4; group $3>$ groups 1, 2; group 4> groups 1, 2

${ }^{\dagger} p<0.10 ; * p<0.05 ; * * p<0.01 ; * * * p<0.001$

in $2009,0.25 \%$ of men and $0.14 \%$ of women in the general population were institutionalized in a mental health facility [21], while it is estimated that $0.32 \%$ of the population experienced incarceration in $2010[10,34]$.

(2) Employment. Men were more likely to be employed $\left(\chi^{2}(1, N=234)=4.34\right.$, $p<.05)$ than women and were also more often employed fulltime $\left(\chi^{2}(1\right.$, 
$N=246)=6.59, p<.05)$. At the time of the interview, $46.6 \%$ of the men $(N=55)$ was employed, and $38.1 \%$ was employed fulltime. Of the women, $37.6 \%$ $(N=50)$ was employed, and $24.1 \%$ was employed fulltime. Still, while being in their 30s, over half of the sample is unemployed, making employment participation in our sample considerably lower than in the general Dutch population [11]. To illustrate, in 2011, employment participation in the Netherlands for men aged 25 to 35 was $86 \%$ and $90 \%$ for men aged 35 to 45 . That same year employment participation for Dutch women was $78 \%$ for those aged 25 to 35 and $74 \%$ for those aged 35 to 45 .

(3) Intimate relationship. At the moment of the interview, almost $60 \%$ of the men and two thirds $(66.7 \%)$ of the women were in a romantic relationship. Of those in a relationship, 45 men $(38.8 \%)$ and 57 women $(43.2 \%)$ cohabit while not being married, and a small proportion of the respondents is married (14.7\% of the men and $9.1 \%$ of the women). Although it is difficult to determine how the number of subjects who are in a relationship relates to the figure in the Dutch population, the percentage of subjects in our sample cohabiting or being married appears to be lower [31].

(4) Regular contact with children. Women were more likely than men to have children $\left(\chi^{2}(1, N=250)=14.95, p<.001\right)$. Almost four out of five women $(78.8 \%)$ had one or more children compared to three out of five men $(55.9 \%)$. The average age at birth of the first child is lower than in the general population, especially for women [56]. Among those who had children, $75.4 \%$ of all fathers and $89.2 \%$ of all mothers reported that they have regular contact with their child(ren), a significant difference $\left(\chi^{2}(1, N=163)=5.42, p<.05\right)$. In the total sample, over half of the respondents $(54.6 \%)$ are classified as having children with whom they have regular (daily or weekly) contact. When asked about the reason for not having regular contact with their children, parents in our sample report conflicts with their ex-partner about custody, or that children were placed under care of the Child Protection Board.

(5) Satisfactory health. About half of the men (50\%) and women (47.6\%) were considered to be in satisfactory health, meaning that they have not had, or only once have had, contact with a health care professional or took medication prescribed by a doctor in the twelve months preceding the interview. Forty-two men $(41.6 \%)$ and 63 women $(52.1 \%)$ had contact with a medical specialist and about one third of the respondents $(30.4 \%$ of men, $N=31$, and $35.6 \%$ of women, $N=42$ ) had contact with one or more mental health care professionals (mental health service, a psychologist or a psychiatrist) in the past year. Furthermore, 45 men $(42.9 \%)$ and 50 women $(40.7 \%)$ reported that they took prescription medication in the past 12 months. In comparison, in 2010, $32.9 \%$ of Dutch citizens between ages 30 and 40 had contact with a medical specialist [8]. In the general population, $6.2 \%$ of those aged between 18 and 64 had contact with a mental health care professional in the past 12 months [14]. Finally, of all Dutch people between ages 20 and 45, 26.8 \% takes medication prescribed by a doctor [8]. Both physical and mental health problems thus appear to be more common among previously institutionalized men and women as compared to the Dutch population as a whole. 
(6) Alcohol abuse. In our sample, $45 \%$ of the men meet the criteria for alcohol abuse in the 12 months prior to the interview, compared to $22 \%$ of the women. This difference is again statistically significant $\left(\chi^{2}(1, N=226)=13.88, p<.001\right)$. Alcohol abuse is considerably higher than in the general Dutch population, where among men aged 25 to $348.7 \%$ and among men aged 35 to $445.6 \%$ meet the criteria for alcohol abuse in the past year. Among Dutch women aged 25 to 34 and women aged 35 to 44, percentages are even lower, respectively, 2.6 and $1.2 \%$ [14].

(7) Drug abuse. While over half of the respondents (56.1\%) report that they did not use any drugs in the past 12 months, over a quarter of the sample $(27.9 \%, 40$ men, 30 women) reports daily or weekly drugs use. Drug abuse in our sample was more prevalent among men than among women $\left(\chi^{2}(1, N=223)=7.18, p<.01\right)$. Over one third of the men $(37.6 \%)$ meet the criteria for drugs abuse in the 12 months prior to the interview, compared to one in five women $(21.3 \%)$. Similar as with alcohol abuse, the figures reported by our sample are substantially higher than those among similarly aged men and women in the general Dutch population. Among Dutch men aged 25 to $342.0 \%$ is considered to have a drug abuse problem, while this is $1.4 \%$ among men aged 35 to 44 . Among women $1.0 \%$ of Dutch women aged 25 to 34 and $0.3 \%$ of Dutch women aged 35 to 44 meet the criteria for drug abuse [14].

(8) Self-reported crime. The majority of respondents report that they did not engage in criminal behaviour in the past 12 months. Among men and women who report that they did commit one or more offenses in the past 12 months (34 men, 34.0\% and 27 women, $25.2 \%$ ), the offenses that are most reported are threatening/assault $(N=36)$, drugs dealing $(N=20)$ and theft $(N=18)$. Self-reported criminal behaviour in this sample appears to be higher than among Dutch men and women. To illustrate, a study by Donker [15] found that among young adults aged 18 to 32 (average age of 24.5), nearly one in four respondents reported to have engaged in criminal behaviour over the past year. Wittebrood et al. [62] showed that in a sample of men and women aged 15 and older (with an average age of 37), less than one in five of the respondents reported committing a crime in the previous year. These studies combined suggest that for the Dutch general population, the prevalence of selfreported crime in (young) adulthood is somewhere between 17 and $24 \%$. Given that the prevalence of offending declines with age, population estimates based on more age-homogeneous samples are expected to be even lower.

Taken together, previously institutionalized men and women experience considerable difficulties in multiple adult life domains. Not surprisingly, the average level of adult life adjustment can be considered as quite low (Table 4). Moreover, men have a significantly lower average level of adult life adjustment $(\mathrm{M}=0.61, \mathrm{SD}=0.28)$ than women $(\mathrm{M}=0.69, \mathrm{SD}=0.22)(\mathrm{t}(224.98)=-2.82, p<0.01)$.

When making a distinction between the different offender groups, the two desisting offender groups show the highest level of adult life adjustment, whereas the two chronic groups show the lowest level of adult life adjustment. An analysis of variance test showed that there is a significant difference in the average levels of adult life adjustment between the groups $(\mathrm{F}(3,247)=15.44, p<.001)$, and the post hoc test showed that average levels of adult life adjustment are significantly lower in the two chronic groups compared to the desisting groups. Furthermore, 
when looking at the different employment trajectories average levels of adult life adjustment are significantly different between these employment groups as well $(\mathrm{F}(3,247)=7.84, p<.001)$. Post hoc tests indicate that the two groups that show an increasing or continuous employment rate with age have significantly higher levels of adult life adjustment than the chronically unemployed group and the group with a decreasing employment rate (Table 4).

\section{The Relationship Between Personal and Childhood Characteristics, Criminal History, Employment History and Adult Life Adjustment}

To examine to what extent subjects' gender, personal and childhood characteristics, their criminal behaviour and employment history are associated with outcomes in adulthood, three multiple regression models are estimated (Table 5). ${ }^{56}$ The first model, which includes subjects' gender, personal and childhood characteristics and education, shows that these variables accounted for a significant amount of the variability in adult life adjustment $\left(R^{2}=.12, F(9,203)=3.09, p<0.01\right)$. Gender has a significant effect on adult life adjustment, indicating that over a decade after leaving the institution girls are doing better in conventional adult life domains than their male counterparts. Furthermore, subjects that did not finish an education after their stay in the institution have lower levels of adult life adjustment. The other personal and childhood risk factors have no significant effect on the level of adult life success.

In Model 2, we examined to what extent criminal history is related to adult life adjustment, while controlling for gender, personal and childhood characteristics and education. In the second model, adding the variables for criminal history significantly improved prediction of adult life adjustment, over and above the personal and childhood characteristics $\left(R^{2}\right.$ change $\left.=.11, F(4,199)=6.72, p<0.001\right)$. Being convicted for a serious offense between ages 12 and 17 has no significant effect on the level of adult life adjustment. However, the model shows that the two groups that have the highest level of criminal behaviour in adulthood, the low-rate chronics and the high-rate chronics, show significantly lower levels of adjustment in adult life domains. ${ }^{7}$ Gender no longer predicts adult life adjustment when criminal history indicators are added to the model, but not finishing an education remains predictive of having more negative life outcomes in adulthood $(p=0.05)$.

The third model shows that when employment patterns are also taken into account, prediction of adult life adjustment is again significantly improved $\left(R^{2}\right.$ change $=.05$, $F(3,196)=4.42, p<0.01)$. Results show that the two chronic offending groups have a significantly lower level of adult life adjustment, whereas the two employment groups that have the highest employment rate show significantly higher levels of adjustment in

\footnotetext{
${ }^{5}$ It must be noted that the variable for adult life adjustment is slightly skewed. To test for robustness of the results, bootstrapping was used. In the bootstrapping procedure, the parameters are calculated using 1000 different subsamples that were randomly sampled from the total sample [18]. The results of the regression analysis using bootstrapping are very similar to the original regression analysis. We are therefore confident that the results are robust.

${ }^{6}$ Post hoc power analyses demonstrated that our sample of 251 respondents is large enough to detect differences, as the power to detect effects at the 0.05 level was 0.99 in regression models 1 and 2 and 0.88 in regression model 3.

${ }^{7}$ Some caution is warranted when interpreting the effects of the conviction trajectories though, as two groups, the high-rate desisters $(11.6 \%, N=29)$ and the high-rate chronics $(9.2 \%, N=23)$ are relatively small.
} 
Table 5 The relationship between personal and childhood characteristics, criminal history, employment history and adult life adjustment

\begin{tabular}{|c|c|c|c|c|c|c|}
\hline & \multicolumn{2}{|l|}{ Model 1} & \multicolumn{2}{|c|}{ Model 2} & \multicolumn{2}{|l|}{ Model 3} \\
\hline & $\mathrm{B}$ & $\mathrm{SE}$ & B & $\mathrm{SE}$ & B & SE \\
\hline Intercept & $.68 * * *$ & .05 & $.75^{* * *}$ & .06 & $.66^{* * *}$ & .07 \\
\hline Gender & $.16^{* * * *}$ & .04 & .07 & .05 & .07 & .04 \\
\hline Low intelligence & -.001 & .04 & .03 & .03 & .04 & .03 \\
\hline Aggression & -.006 & .04 & -.01 & .04 & -.002 & .04 \\
\hline Impulsiveness & -.001 & .04 & .00 & .03 & .001 & .03 \\
\hline Psychological problems & -.01 & .04 & -.01 & .04 & -.01 & .03 \\
\hline Problems in the family & -.02 & .02 & -.01 & .01 & -.01 & .01 \\
\hline Victimization & -.003 & .02 & .004 & .02 & .01 & .02 \\
\hline No diploma during institutionalization & -.05 & .04 & -.03 & .04 & -.001 & .04 \\
\hline No diploma after institutionalization & $-.09 * *$ & .03 & $-.06 \dagger$ & .03 & -.04 & .03 \\
\hline Convicted < age 18 & & & -.03 & .04 & -.04 & .04 \\
\hline \multicolumn{7}{|l|}{ Crime trajectories $>18$} \\
\hline Group 2: high-rate desisters & & & .05 & .07 & .01 & .07 \\
\hline Group 3: low-rate chronics & & & $-.18 * *$ & .05 & $-.16^{* *}$ & .05 \\
\hline Group 4: high-rate chronics & & & $-.20^{* *}$ & .07 & $-.18^{*}$ & .07 \\
\hline \multicolumn{7}{|l|}{ Employment trajectories $>18$} \\
\hline Group 2: decreasing employed & & & & & -.04 & .05 \\
\hline Group 3: increasing employed & & & & & $.11 *$ & .05 \\
\hline Group 4: continuously employed & & & & & $.10^{*}$ & .05 \\
\hline $\mathrm{R}^{2}$ & .12 & & .23 & & .27 & \\
\hline
\end{tabular}

${ }^{\dagger} p<0.10 ; * p<0.05 ; * * p<0.01 ; * * * p<0.001$

adult life domains. The effect of education on adult outcomes is no longer significant in Model 3, suggesting that much of the effect of education on adult life adjustment materializes through having more stable employment careers. Still, the percentage explained variance in Model 3 is still quite low $\left(R^{2}=.27\right)$, indicating that adult life adjustment is only modestly explained by personal and childhood characteristics, criminal history and employment history.

\section{Discussion}

Building on previous work examining the adult outcomes of offending behaviour earlier in life [17, 29, 39, 43, 47], this study examined levels of adult life adjustment at an average age of 34 of previously institutionalized men and women $(N=251)$ who were treated for serious problem behaviour in a Dutch juvenile justice institution in the 1990s. Data on personal and childhood characteristics, officially registered data on criminal convictions, in addition to retrospective self-report data on employment history (collected using a life history calendar) and several important adult life domains 
enabled us to study effects of a vulnerable background, criminal history and employment history on adult life adjustment.

Results showed that the backgrounds of previously institutionalized youths are characterized by serious problem behaviour, psychological problems, victimization, an adverse family situation and academic failure. In young adulthood, over $80 \%$ of the men and almost $50 \%$ of the women were convicted of an offense. Using group-based trajectory modeling, four distinct offender groups were identified: low-rate desisters, high-rate desisters, low-rate chronics and high-rate chronics. Although the majority of men and women find a job at some point during the observation period, their work histories are unstable and they are employed for only little over half of the observation period on average. Group-based trajectory modeling revealed the existence of four different employment groups in the sample: a chronically unemployed group, a group with decreasing employment rates, one with increasing employment rates and a continuously employed group.

Moreover, this study showed that a large part of the men and women experienced difficulties in conventional life domains when they are well into their 30s. Compared to the general Dutch population, they fare worse on all measured life domains: the number of sample members institutionalized is higher, employment participation is lower, there is less family formation, a higher rate of contact with (physical and mental) health care professionals, more alcohol and drug abuse and more (self-reported) criminal behaviour. All in all, the average level of overall adult life adjustment is considered to be low in this sample. Furthermore, outcomes for previously institutionalized men are significantly worse than for women.

While taken together, this sample of previously institutionalized youths thus represents a specifically vulnerable group, with many of the men and women under study having experienced considerable difficulties in both their childhoods and adult lives, meaningful subgroups still may be present. Regression models were therefore used to examine the relationship between gender, personal and childhood characteristics, criminal history, employment history and adult life adjustment in this group. The models showed that most of the individual and childhood characteristics, except for academic failure, are not significantly related to adult life adjustment. Criminal behaviour does impact adult life outcomes, as the two chronic offender groups show more difficulties in conventional adult life domains. Employment, on the other hand, is associated with better adult outcomes, as the two employment groups that have an increasing or high employment rate in adulthood show a higher level of adult life adjustment. Although the variance explained by the models is quite low, adult life adjustment appears to be mainly explained by events during adulthood, and not so much by childhood risk factors, at least within this institutionalized sample. This suggests that it is difficult to identify those vulnerable youths who are most at risk of failing to adopt adult roles based on childhood characteristics. The results therefore do not lend much support for the static view that adult life outcomes can be explained solely by stable individual characteristics [25]. However, it is important to note that childhood risk factors averaged high in this sample, meaning that childhood risk factors may have predictive value in lower-risk samples (compare [47]). For this sample of vulnerable youths, the results indicate that behavioural patterns in adulthood matter most for later life outcomes. On the one hand, the findings indicate that criminal behaviour later in life can negatively influence adult outcomes, which is in line with 
the assumption that deviant labeling can diminish or block conventional opportunities in adulthood (e.g. [3]) and that disadvantage can accumulate over the life course [52]. These results are comparable to those of Piquero et al. [47], who also found that chronic offenders were least successful in conventional adult domains at age 48. Findings with regard to employment patterns seem in line with the work of Sampson and Laub [51], who argue that ties to social institutions such as employment can bring about positive change in the life course. For those youths who are able to find employment, work appears to facilitate transitions in other life domains, thereby promoting life success in adulthood.

In the current study, vulnerable girls showed more childhood risk factors than did boys, which corroborates previous research suggesting that delinquent girls are characterized by a more problematic background than are criminal boys [16]. However, the adult outcomes of vulnerable women are better than those of their male counterparts. Despite girls having more troubled backgrounds, boys more often grow up to develop a (persistent) criminal career in adulthood, a result also found in the Nilsson and Estrada study [43]. Because of their higher level of criminal behaviour, men might be more likely to become trapped in a downward spiral of cumulative disadvantage, making it increasingly difficult to adapt to adult roles [52]. Since research on the long-term outcomes of vulnerable youths, and particularly females, is scarce, future research is needed to test for the mechanisms underlying these gender differences.

The strengths of this study lie in the contemporary sample of both men and women, and the attention paid to non-crime outcomes when subjects are well into their $30 \mathrm{~s}$. Some limitations of the study must be noted as well. To begin with, it is important to keep in mind that the sample under study represents a very specific and vulnerable group that exhibited problem behaviour deemed so serious that they were institutionalized. Despite the sample as a whole stemming from the tail of the risk factor distribution however, we still find ample variation in both childhood factors, developmental trajectories as well as adult outcomes. Childhood risk factors averaging high in this sample may influence the generalizability of our findings. While in the current sample childhood risk factors were not significantly related to lower levels of adult life adjustment, this might be different in lower-risk or general population samples (e.g. [47]). Moreover, for this study, personal and childhood factors were extracted from treatment files, and several variables were dichotomized for the analyses. A more sophisticated measurement of background variables in future research might produce more nuanced findings on the relationship between childhood risk factors and adult outcomes among vulnerable youths.

Furthermore, our findings indicate that both offending and employment patterns in adulthood are related to adult outcomes. It must be noted, however, that, like in the study by Piquero and colleagues on the Cambridge data [47], our measure of adult life adjustment includes the domains of employment and (self-reported) criminal involvement. To avoid overlap between the independent and dependent variables, employment and crime trajectories were estimated up to 1 year before the interview, while adult life adjustment was measured at the time of the interview. Still, continuity in employment and offending patterns is likely and this might to some extent explain the observed relationship between employment and offending patterns and adult outcomes. Based on theoretical (employment is one of the most important adult life domains) and methodological reasons (excluding these domains from our outcome variable resulted in a less 
reliable scale of adult life adjustment), we have chosen to report results from analyses including these variables in our outcome measure. Additional analyses excluding both self-reported crime and employment from our adult life adjustment scale were however largely comparable, the only difference being that, while being in the same direction, the effects of the employment trajectories are slightly smaller in magnitude and no longer reach significance. ${ }^{8}$

Importantly, data on a comparison group was regrettably unavailable, making it difficult to determine which factors are causing the generally poor adult outcomes observed in the sample. In future research, for instance, inclusion of a comparison group characterized by a vulnerable background but without having experienced institutionalization, would help shed light on the extent to which institutionalization significantly contributes to poorer adult outcomes (e.g. [22]).

In addition, as mentioned in the 'Methods' section, those that were without an officially registered home address and could not be traced via shelters in the municipality of last known residence and those that had died after leaving the juvenile justice institution could not be included in the subsample under study. Given that being homeless (and the conditions usually surrounding homelessness) rank near the bottom of our life adjustment scale, and that premature death can be viewed as the worst possible adult outcome, our findings on the levels of adult life adjustment in previously institutionalized youths may to some extent be positively biased.

Furthermore, while our measure of adult life adjustment may be regarded as 'conservative', as no information on subjective appraisals was taken into account, dichotomous indicators of adult outcomes may also overestimate the true level of adult life adjustment. For one, respondents may live in a run-down rental apartment in a notoriously bad neighborhood, work a low-paying dead-end job and be involved in a conflict ridden relationship, and still be considered 'well adjusted'. Second, for many of the indicators used, longitudinal measures of stability are lacking: respondents may (be forced to) move house every 6 months, or engage in numerous short-lived relationships. Whereas the data used in this study enabled us to examine adult outcomes in a certain year, just as in the Nilsson and Estrada [43] study, Farrington et al. [17] measured life success in the last 5 years to take possible instability in adult outcomes into account. Finally, the subjective experience of the level of adjustment in different adult life domains might differ between people, as they might have different expectations of attaining certain adult roles and different definitions of when they consider themselves as doing well in adult life domains. This indicates that it is difficult to compose an 'objective' measure of adult life adjustment [13, 49]. Future research therefore might employ relative measures, like those used in health research, asking respondents about their perceived life success relative to the level of success achieved by others whom they perceive as their peers (e.g. [36]).

Moreover, for this study, education was treated as an independent variable, and results showed that academic failure is related to poorer adult outcomes. However, academic achievement might be considered an outcome and thus part of the adult life adjustment measure, given that childhood risk factors and delinquency in adolescence can be related to academic failure (e.g. [26]). Nevertheless, since this study focuses on adult outcomes when previously institutionalized youths are in their $30 \mathrm{~s}$, and academic

\footnotetext{
${ }^{8}$ Results for these additional analyses are available from the authors.
} 
attainment generally takes place earlier in life, we decided to include educational attainment as a predictor of later adult outcomes. Finally, in this study, we relied on officially registered data on criminal convictions to reconstruct respondents' juvenile and adult criminal histories, which means the actual number of offenses committed is likely to be underestimated.

To close, this study showed that a substantial part of previously institutionalized youths continues to experience difficulties in multiple adult life domains. This indicates that, although the Dutch welfare state is characterized by a strong social safety net, vulnerable youths in the Netherlands are in need of additional support to help them make a successful transition into adulthood. While interventions during institutionalization are the most obvious as they are relatively easy to implement, the current results suggest that vulnerable youths can especially benefit from intensive support after institutionalization, continuing into young adulthood, to help them establish themselves as adults. Interventions aimed at strengthening the position of vulnerable young adults on the labor market, for example through investment in education and vocational skills, seem especially important. A qualitative study carried out on the same sample of previously institutionalized youths suggests that after they had been discharged from the institution, these youths hardly received any aftercare. Respondents reported that in their opinion they would have benefitted from education and support to find work and accommodation [56]. Providing vulnerable youths with the right support to improve their adult outcomes is desirable to promote these youths' quality of life, as well as to reduce the high costs they impose on society, in terms of their criminal behaviour, unemployment, welfare dependency and extensive use of health care [37, 48].

\section{References}

1. American Psychiatric Association. (Ed.). (2000). Diagnostic and statistical manual of mental disorders: DSM-IV-TR. Washington: American Psychiatric Pub.

2. Arnett, J. J. (2000). Emerging adulthood: a theory of development from the late teens through the twenties. American Psychologist, 55(5), 469-480.

3. Becker, H. (1963). Outsiders: studies in the sociology of deviance. New York: Free Press.

4. Bernburg, J. G., \& Krohn, M. D. (2003). Labeling, life chances, and adult crime: the direct and indirect effects of official intervention in adolescence on crime in early adulthood. Criminology, 41, 1287-1318.

5. Bushway, S. D., Nieuwbeerta, P., \& Blokland, A. (2011). The predictive value of criminal background checks: do age and criminal history affect time to redemption? Criminology, 49(1), 27-60.

6. Caspi, A., \& Moffitt, T. E. (1995). The continuity of maladaptive behavior: from description to understanding in the study of antisocial behavior. In D. Cicchetti \& D. J. Cohen (Eds.), Developmental Psychopathology (Risk, Disorder, and Adaptation, Vol. 2, pp. 472-511). New York: Wiley.

7. CBS Statline [Statistics Netherlands] (2013a). Sterftetabellen [Death rate]. http://www.statline.cbs.nl. Accessed 1 May 2013.

8. CBS Statline [Statistics Netherlands] (2013b). Medical specialist and medication use. http://statline.cbs. $\mathrm{nl} /$ StatWeb/publication/?DM=SLNL\&PA=7042MC\&D1=122-123,129,140,360-361,367\&D2=0-1,5,10 ,15,1\&HDR=G1\&STB=T\&VW=T. Accessed 5 May 2013.

9. CBS Statline [Statistics Netherlands] (2013c). In justitiële jeugdinrichting, strafrechtelijke titel (12 tot 18 jaar). [In juvenile justice institution, criminal law measure (ages 12 to 18)]. http://jeugdmonitor.cbs.nl/nl$\mathrm{NL} / \mathrm{menu} /$ indicatoren/justitie/in-just-jeugdinrichting-strafr-titel.htm?showindicators=true. Accessed 30 May 2013.

10. CBS Statline [Statistics Netherlands] (2013d). Personen in institutionele huishoudens [Persons in institutions]. http://statline.cbs.nl/StatWeb/publication/?DM=SLNL\&PA=37620\&D1=a\&D2=0\&D3=0,103,105 , 107\&D4 = 0,5,10,15-17\&HDR = T\&STB = G1,G2,G3\&VW= T. Accessed 19 June 2013. 
11. CBS Statline [Statistics Netherlands] (2013e). Employment participation. http://statline.cbs.nl. Accessed 30 May 2013.

12. Chung, H. L., Little, M., \& Steinberg, L. (2005). The transition to adulthood for adolescents in the juvenile justice system: a developmental perspective. In W. D. Osgood, E. M. Foster, C. Flanagan, \& G. R. Ruth (Eds.), On your own without a net: The transition to adulthood for vulnerable populations (pp. 68-91). Chicago: University of Chicago Press.

13. Crosnoe, R., \& Elder, G. H., Jr. (2002). Successful adaptation in the later years: a life course approach to aging. Social Psychology Quarterly, 65(4), 309-328.

14. De Graaf, R., Ten Have, M., \& Van Dorsselaer, S. (2010). De psychische gezondheid van de Nederlandse bevolking: NEMESIS-2: opzet en eerste resultaten. Utrecht: Trimbos-instituut.

15. Donker, A. G. (2004). Precursors and prevalence of young-adult and adult delinquency (Doctoral dissertation). Leiden: Universiteit Leiden.

16. Eme, R. F. (1992). Selective female affliction in the developmental disorders of childhood: a literature review. Journal of Clinical Child Psychology, 21, 354-364.

17. Farrington, D. P., Coid, J. W., Harnett, L. M., Jolliffe, D., Soteriou, N., Turner, R. E. \& West, D. J. (2006). Criminal careers up to age 50 and life success up to age 48: New findings from the Cambridge study in delinquent development (Home Office Research Study No. 299). London: Home Office.

18. Field, A. (2013). Discovering statistics using IBM SPSS Statistics (4th ed.). London: Sage.

19. Freedman, D., Thornton, A., Camburn, D., Alwin, D., \& Young-DeMarco, L. (1988). The life history calendar: a technique for collecting retrospective data. Sociological Methodology, 18, 37-68.

20. Gemeenschappelijke Gezondheidsdienst (2005). GGD Health Monitor. Derived from https://www. monitorgezondheid.nl/volksindicatoren.aspx.

21. Gijsen, R. \& Poos, M. (2013). Wat is het zorggebruik? In: Volksgezondheid Toekomst Verkenning, Nationaal Kompas Volksgezondheid. Bilthoven: RIVM, accessed on 15 December 2015, via http:/www. nationaalkompas.nl/zorg/huidig-zorggebruik/

22. Gilman, A. B., Hill, K. G., \& Hawkins, J. D. (2015). When is a youth's debt to society paid? Examining the long-term consequences of juvenile incarceration for adult functioning. Journal of Developmental and Life-Course Criminology, 1(1), 33-47.

23. Glueck, S., \& Glueck, E. (1950). Unraveling juvenile delinquency. New York: Commonwealth Fund.

24. Glueck, S., \& Glueck, E. (1968). Delinquents and nondelinquents in perspective. Cambridge, Mass: Harvard University Press.

25. Gottfredson, M. R., \& Hirschi, T. (1990). A general theory of crime. Stanford: Stanford University Press.

26. Hinshaw, S. P. (1992). Externalizing behavior problems and academic underachievement in childhood and adolescence - causal relationships and underlying mechanisms. Psychological Bulletin, 11(1), 127-155.

27. Hulin, C. L. (2002). Lessons from industrial and organizational psychology. In J. Brett \& F. Drasgow (Eds.), The psychology of work: theoretically based empirical research (pp. 3-22). Mahwah: Erlbaum.

28. Jahoda, M. (1982). Employment and unemployment. A social-psychological analysis. Cambridge: Cambridge University Press.

29. Jennings, W. G., Rocque, M., Fox, B. H., Piquero, A. R., \& Farrington, D. P. (2016). Can they recover? An assessment of adult adjustment problems among males in the abstainer, recovery, life-course persistent, and adolescence-limited pathways followed up to age 56 in the Cambridge Study in Delinquent Development. Development and Psychopathology, 28(02), 537-549.

30. Jeugdzorg Nederland [Youth care the Netherlands]. (2013). Brancherapportage Jeugdzorg 2011. Utrecht: Jeugdzorg Nederland.

31. Latten, J. (2004). Trends in samenwonen en trouwen. De schone schijn van burgerlijke staat. [Trends in cohabitation and marriage]. Centraal Bureau voor Statistiek, Bevolkingstrends, 4e kwartaal 2004.

32. Laub, J. H., \& Sampson, R. J. (2003). Shared beginnings, divergent lives; Delinquent Boys to age 70. Cambridge: Harvard University Press.

33. Lemert, E. (1967). Human deviance, social problems and social control. Englewood Cliffs: Prentice Hall.

34. Linckens, P., \& De Looff, J. (2013). Gevangeniswezen in getal, 2008-2012. Den Haag: Dienst Justitiële Inrichtingen.

35. Loeber, R., Farrington, D. P. \& Waschbusch, D.A. (1998). Serious and Violent Juvenile Offenders. Risk Factors and Successful Interventions, (Eds.), (pp. 13-29) R. Loeber and D. P. Farrington. Thousand Oaks, CA: Sage.

36. McDowell, I. (2006). Measuring health: a guide to rating scales and questionnaires (3rd ed.). New York: Oxford University Press.

37. Moffitt, T. E. (1994). Natural histories of delinquency. In E. G. M. Weitekamp \& H. Kerner (Eds.), CrossNational Longitudinal Research on Human Development and Criminal Behavior (pp. 3-61). Dordrecht: Kluwer. 
38. Moffitt, T. E., \& Caspi, A. (2001). Childhood predictors differentiate life-course persistent and adolescence-limited antisocial pathways among males and females. Development and Psychopathology, $13,355-375$.

39. Moffitt, T. E., Caspi, A., Harrington, H., \& Milne, B. J. (2002). Males on the life-course- persistent and adolescence-limited antisocial pathways: follow-up at age 26 years. Development and Psychopathology, 14(01), 179-207.

40. Nagin, D. S. (1999). Analyzing developmental trajectories: a semiparametric, group-based approach. Psychological Methods, 4(2), 139-157.

41. Nagin, D. S. (2004). A semi-parametric, group-based approach for analyzing trajectories of development: a non-technical overview. Pp. 247-259 in Punishment, Places and Perpetrators: Developments in Criminology and Criminal Justice Research. Edited by G. Bruinsma, H. Elffers, and J. de Keijser. Devon, UK: Willan.

42. Nagin, D. S. (2005). Group-based modeling of development. Cambridge: Harvard University Press.

43. Nilsson, A. \& Estrada, F. (2009). Criminality and life-chances. A longitudinal study of crime, childhood circumstances and living conditions up to age 48. Department of Criminology Report Series, Report 2009:3.

44. Osgood, D. W., Foster, E. M., Flanagan, C., \& Ruth, G. R. (2005). On your own without a net: The transition to adulthood for vulnerable populations. Chicago: University of Chicago Press.

45. Paul, K. I., \& Batinic, B. (2010). The need for work: Jahoda's latent functions of employment in a representative sample of the German population. Journal of Organizational Behavior, 31(1), 45-64.

46. Piquero, A. R., Brame, R., Mazerolle, P., \& Haapanen, R. (2002). Crime in emerging adulthood. Criminology, 40(1), 137-169.

47. Piquero, A. R., Farrington, D. P., Nagin, D. S., \& Moffitt, T. E. (2010). Trajectories of offending and their relation to life failure in late middle age: findings from the Cambridge study in delinquent development. Journal of Research in Crime and Delinquency, 47(2), 151-173.

48. Piquero, A. R., Jennings, W. G., \& Farrington, D. (2013). The monetary costs of crime to middle adulthood: findings from the Cambridge study in delinquent development. Journal of Research in Crime and Delinquency, 50(1), 53-74.

49. Pulkkinen, L., Nygren, H., \& Kokko, K. (2002). Successful development: Childhood antecedents of adaptive psychosocial functioning in adulthood. Journal of Adult Development, 9(4), 251-265.

50. Rutter, M., Quinton, D., \& Hill, J. (1990). Adult outcomes of institution-reared children: males and females compared. In L. N. Robins \& M. Rutter (Eds.), Straight and devious pathways from childhood to adulthood (pp. 135-157). Cambridge: Cambridge University Press.

51. Sampson, R. J., \& Laub, J. H. (1993). Crime in the making: pathways and turning points through life. Cambridge: Harvard University Press.

52. Sampson, R. J., \& Laub, J. H. (1997). A life-course theory of cumulative disadvantage and the stability of delinquency. In T. P. Thornberry (Ed.), Developmental theories of crime and delinquency (pp. 1-29). New Brunswick: Transaction.

53. Tanner, J., Davies, S., \& O'Grady, B. (1999). Whatever happened to yesterday's rebels? Longitudinal effects of youth delinquency on education and employment. Social Problems, 46, 250-274.

54. Uggen, C., \& Wakefield, S. (2005). Young adults reentering the community from the criminal justice system: the challenge of becoming an adult. In D. W. Osgood, E. M. Foster, C. Flanagan, \& G. R. Ruth (Eds.), On your own without a net: The transition to adulthood for vulnerable populations (pp. 114-144). Chicago: University of Chicago Press.

55. Van der Geest, V. R., Blokland, A. A. J., \& Bijleveld, C. C. J. H. (2009). Delinquent development in a sample of high-risk youth shape, content, and predictors of delinquent trajectories from age 12 to 32 . Journal of Research in Crime and Delinquency, 46(2), 111-143.

56. Van der Geest, V., Bijleveld, C., \& Verbruggen, J. (2013). Vallen en opstaan. Mannen en vrouwen 17 jaar na vertrek uit een justitiële jeugdinrichting. Amsterdam: Vrije Universiteit en Nederlands Studiecentrum Criminaliteit en Rechtshandhaving.

57. Verbruggen, J., Blokland, A., \& Van der Geest, V. (2012). Effects of employment and unemployment on serious offending in a high-risk sample of men and women from ages 18 to 32 in the Netherlands. British Journal of Criminology, 52(5), 845-869.

58. Verbruggen, J., Apel, R., Van der Geest, V., \& Blokland, A. (2015). Work, income support, and crime in the Dutch welfare state: a longitudinal study following vulnerable youth into adulthood. Criminology, 53(4), 545-570.

59. Verhulst, F. C., van der Ende, J., Ferdinand, R. F., \& Kasius, M. C. (1997). The prevalence of DSM-III-R diagnoses in a national sample of Dutch adolescents. Archives of General Psychiatry, 54(4), 329.

60. Wartna, B. S. J., Kalidien, S. N., Tollenaar, N., \& Essers, A. A. M. (2006). Strafrechtelijke recidive van jongeren uit justitiële jeugdinrichtingen. Den Haag: Wetenschappelijk Onderzoek- en Documentatiecentrum. 
61. Werner, E. (1989). High-risk children in young adulthood: a longitudinal study from birth to 32 years. American Journal of Orthopsychiatry, 59, 72-81.

62. Wittebrood, K., Michon, J. A., \& ter Voert, M. J. (1997). Nederlanders over criminaliteit en rechtshandhaving. Leiden: Gouda Quint, Nederlands Studiecentrum Criminaliteit en Rechtshandhaving. 